\title{
On the Mineral and Vegetal Oils Used as Electroinsulation in Transformers
}

\author{
Mariana Şerban, Livia Sângeorzan, and Elena Helerea \\ Transilvania University of Brasov, \\ 29 Eroilor Str., 500036 Brasov, Romania \\ helerea@unitbv.ro
}

\begin{abstract}
Due to the relatively large availability and reduced price, the mineral transformer oils are widely used as electrical insulating liquids. However, mineral oil drastically degrades over time in service. New efforts were made to improve mineral oils characteristics, and other types of liquids like vegetal oils are proposed. This paper deals with new comparative tests on mineral and vegetal oils using as indicator the electric strength. The samples of non-additive mineral oil type TR 30 and vegetal oils of rape, sunflower and corn have been tested with increasing voltage of $60 \mathrm{~Hz}$ using different electrodes. The obtained data have been statistical processed. The analyze shows different average values of electrical strength for the different type of sample. New method of testing through electrical breakdown is proposed. Experimental data confirms that it is possible to use as electroinsulation organic vegetal oils in power transformers.
\end{abstract}

Keywords: Mineral oil, vegetal oil, electrical breakdown testing, statistic processing, electrode effect.

\section{Introduction}

Intensification of global warming, leading to environmental destruction, implicitly human health, and acute crisis of raw materials and energy have increased. In recent years new researches to find clean alternative green energy resources, replacing nonrenewable resources with new renewable and environmentally friendly resources have been developed.

The global crisis of raw material resources, including oil resources, negatively affects the energy industry [1]. One research direction is to improve the performance of high power electrical transformers, and in particular, of electrical insulation systems. Replacing oil as feedstock for the manufacture of transformer oil should meet the requirements imposed on electrical insulation of high voltage insulation of power transformers [2]. One possibility is to use vegetal oils which are both clean and renewable [3]. There are different variants of oil research, seeking practical solutions to the partial or total replacement of mineral oils with other oils, such as the plant oils [4]. Condition assessment of aging and the estimation of the lifetime average insulation systems used in high power equipment, is today an important research objective for producers and users [5], [6]. 
This paper makes reference to the comparative analysis of traditional vegetal oils and minerals and determines some of their alternative use in high power transformers. The aim is to develop a testing methodology based on nondestructive insulating oils methods that allow comparative analysis between different types of electrical insulating oils.

\section{Contribution to Technological Innovation}

Current challenges related to implementing strategies for sustainable development of human society require the development of new technological innovations. Energy is highly relevant in this respect, to increase energy efficiency and to reduce consumption of scarce raw materials.

In the transport of electricity domain, the issue is diverse, lifetime supply systems and electricity supply being directly linked to good operating condition of high power transformers. The possibilities of replacing the transformer mineral oil, polluting, other dielectric materials such as liquid vegetable oils from plants, green, clean and renewable are under research. The characteristics of the insulation used, in particular transformer oil, establish the good function of the transformer. There are standard methods for determining the characteristics of transformer oil.

Other aspects are that, the current conditions have changed:

$\checkmark$ have appeared new types of oils, namely the inclusion of categories of vegetable oils in study of transformer insulation;

$\checkmark$ regulating devices firms proposed building test equipment according to specific standards, which do not meet specific conditions (which are very different from the request insulation);

$\checkmark \quad$ insulating oil stiffness values as a parameter characteristic of electrical resistance applications depend on a number of intrinsic and extrinsic factors, which are not always specify the companies producing electrical insulating oils;

$\checkmark$ data processing methods usually statistical distribution of normal type, not always applicable in the case of variable data strings.

This paper proposes an experimental analysis for different types of electrical insulating oils - mineral and vegetal - to optimize the dielectric rigidity test methodology and establish the optimal matrix properties necessary in comparative tests of insulating oils.

\section{Challenges on Electrical Transformer Oils}

The insulating oil has a dual role in the complex system of electrical insulation system of power transformers, as a cooling medium and as a medium of electrical insulation. Characteristic of the insulation, in particular of transformer oil, is to largely maintain the good functioning of the transformer.

Mineral oils are a very complex mixture, which can reach about 2900 types of molecules of paraffin, naphthen and aromatic hydrocarbons, their properties can vary greatly from one batch to another, even if they come from the same batch and even the same name. 
Efforts are being made today for rapid and effective establishment of criteria for comparing electrical characteristics of the different types of oils that could run for classes of oils used in electrical insulation systems [2].

The lifetime of transformer oil and its technical performance of operation, depend primarily on its initial quality and then on the operating conditions. As the adverse effects on the ability of insulation occur almost immediately after using the new oil refinery delivered, a special attention was paid to a set of defining characteristics of new oil and control methods of these features, before oil supply to the recipient.

The results of fast quality control methods of electrical oils, are unusually reported. The possibility of developing methods for determining the basic indicators of insulating oils - like dielectric loss angle tangent, or tangent of $\delta$, and stiffness are continuously studied and modern models are being tried to be advantageous in terms of price and cost [1], [2].

It was found that one of the main causes of decline of oil dielectrics electrical parameters (such as modification of loss angle tangent of the dielectric rigidity or other physic - chemical, organic acid, water content, etc.) is the formation of free radicals causing the formation of colloidal structures which disturb electrical insulating performance [4].

Similar concerns are found in other countries (USA, England, Belgium, etc.) the specialized technical literature noting that manufacturers use different processes transformer oil refinery to produce products similar to those already known [3]. The power transformers in the Romanian power system use only mineral insulating oil, resulting from refining crude oils selected for this purpose, in most cases being used transformer oil type TR 30 (non-additive oil) and, type TR 25 A (additive oil).

As the current conditions have changed a new approach is acquired to replace the liquid electrical insulation materials with newer more efficient ones. There are studies about the possibilities of replacing the transformer mineral oil, with other dielectric materials such as liquid vegetal oils from plants, green, clean and renewable.

There are also the standard methods for determining the characteristics of transformer oil [5]. Some firms propose building test equipment according to specific standards, but not always they meet specific conditions (which are very different from the request insulation).

It notes also that the insulating oil electric strength, as a parameter characteristic of electrical insulating capacity, depends on a number of intrinsic and extrinsic factors, which are not always specified by the companies producing electrical insulating oils.

Data processing methods, usually with statistical distribution of normal type, are not always applicable in the case of variable data strings.

\section{Experimental Data}

Measurements were carried out to determine the electric breakdown voltage of different samples of mineral and vegetal oils: non-additive TR 30 oil, sunflower, corn and rapeseed oils.

The Megger AF 60/2 equipment has been used (Fig. 1). The electrodes of test vessel have different shapes: plane, sphere and semi-sphere, and could be set at different distances. A magnetic stirring could be produced by a rotating magnetic field, controlled by software. A thermometer of BK PRECISION 710 type measures the temperature of the oil and the ambient environment. 

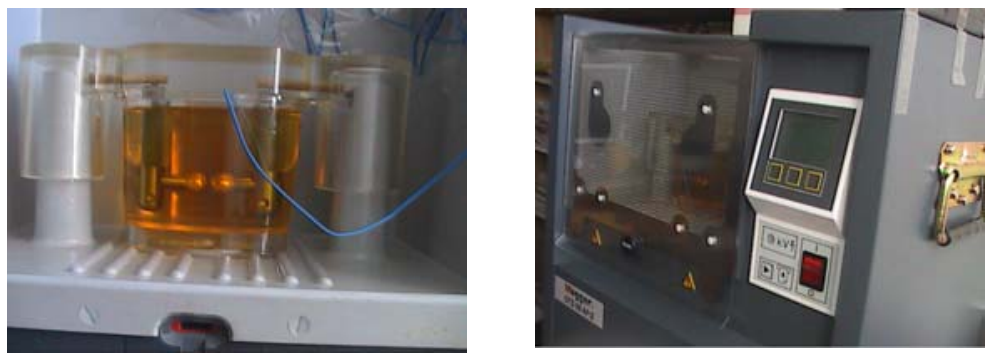

Fig. 1. Equipment for oil electrical breakdown testing

Samples of oil have been subjected to increasing voltage up to breakdown of sample, with a rate of $2.5 \mathrm{kV} / \mathrm{s}$ and frequency of $61.8 \mathrm{~Hz}$. A distance of $1 \mathrm{~mm}$ between electrodes for each type of electrodes - plane, calotte and sphere - has been fixed. The volume of oil used in each test subject to breakdown was $300 \mathrm{~cm}^{3}$. The temperature of oil and ambient environment was of $25-28^{\circ} \mathrm{C}$. The results of breakdown voltage have been saved by a non-volatile memory.

\section{Proceeding of Data and Results}

Measured data were statistically processed. Various statistic parameters have been calculated and histograms have been plotted to reveal the distribution of these measurements. Date proceeding was made using the software Statistics.

\subsection{Statistical Distributions}

Statistical distribution laws, which provide theoretical models as an approximation of measured values for random variables, have been analyzed.

The normal distribution function is determined by the following formula:

$$
f(x)=\frac{1}{\sigma \sqrt{2 \pi}} e^{-\frac{(x-m)^{2}}{2 \sigma^{2}}},
$$

where: $\mu$ is the mean, $\sigma$ is the standard deviation, $e$ is Euler's constant.

The lognormal distribution is often used in simulation of variables. In general, if $x$ is a sample with a normal distribution, then $y=e^{x}$ is a sample with a lognormal distribution. Thus, the lognormal distribution is defined as:

$$
f(x)=\frac{1}{x \cdot \sigma \cdot \sqrt{2 \pi}} e^{-\left[\frac{(\ln (x)-\mu)^{2}}{2 \sigma^{2}}\right]}
$$

where: $\mu$ is the estimated population mean, $\sigma$ is the estimated population standard deviation. 
The Gamma distribution is defined as:

$$
f(x)=\left[\frac{1}{\Gamma(\alpha) \cdot \beta^{\alpha}} e\right] \cdot x^{\alpha-1} \cdot e^{-\frac{x}{\beta}}
$$

where: $\Gamma$ is the Gamma function of argument alpha, $\alpha$ is the so-called shape parameter, and $\beta$ is the so-called scale parameter. For $\alpha=1$, the exponential distribution is obtained.

The Weibull distribution is commonly used in lifetime random data analysis. The Weibull distribution takes values in the range $x>=0$ and has one scale parameter, $\beta$, and one shape parameter, $\alpha$, both of which must be positive.

\subsection{Concordance Tests and Variability Coefficient}

The coefficient of variation $V$ is a synthetic indicator of random data variations and brings information on the homogeneity of the studied lot of samples.

As the percentage ratio between standard deviation and arithmetic mean, coefficient of variation $V$ can range between $0-100 \%$. If the coefficient of variation tends to zero is considered a low variation, a corporate uniform and averaged a high degree of representativeness. If the coefficient of variation tends to $100 \%$, is considered an intense change, and a heterogeneous community with a low average of representativeness. Thus 4 thresholds of representativeness could be considered:

$$
\begin{array}{lll}
\checkmark & 0<\mathrm{V}<17 \% & \text { - mean is strictly representative (has high homogeneity). } \\
\checkmark & 17 \%<\mathrm{V}<35 \% & \text { - mean is moderately representative (less homogeneous). } \\
\checkmark & 35 \%<\mathrm{V}<50 \% & \text { - mean is broadly representative (less homogeneous). } \\
\checkmark & \mathrm{V}>50 \% & \text { - mean unrepresentative (lack of homogeneity). }
\end{array}
$$

An important aspect of the description of the variables is the shape of its distribution, which shows how frequent the values are from different ranges of the variable. Typically a researcher is interested in how well the distribution can be approximated by the normal distribution. Some precise information can be obtained by performing one of the tests of normality to determine the probability that the sample came from a normal distributed population of observations. However, none of these tests can entirely substitute for a visual examination of the data using a histogram. The graph allows the evaluation of the normality of the empirical distribution because it also shows the normal curve superimposed over the histogram. It also allows the examination of various aspects of the distribution qualitatively.

The concordance tests verify if the empirical distribution differs a lot or does not differ from the proposed theoretical distribution. The Kolmogorov-Smirnov test, Shapiro-Wilks'W test, $\chi^{2}$ test are the most used as concordance tests [7].

\subsection{Results of Breakdown Voltage Tests}

The empirical distribution parameters calculated for the four types of random variables data - voltage breakdown of TR 30 mineral oil, sun flower oil, corn oil, rapeseed oil - tested with sphere, plan and calotte electrodes - are given in Table 1, Table 2 and Table 3. 
Table 1. Empirical parameters and estimated parameters of the distribution statistical lows obtained for the series of variables of breakdown voltage $(\mathrm{kV})$ for Mineral Oil, Sun Flower Oil, Corn Oil, Rapeseed Oil, with sphere-sphere electrodes

\begin{tabular}{|c|c|c|c|c|}
\hline \multirow{2}{*}{$\begin{array}{l}\text { Empirical } \\
\text { Distribution } \\
\text { Parameters } \\
\text { (Sphere electrodes) }\end{array}$} & \multicolumn{4}{|c|}{ Type of Random Variables } \\
\hline & $\begin{array}{l}\text { Mineral Oil } \\
\text { TR } 30\end{array}$ & $\begin{array}{c}\text { Sun Flower Oil } \\
\text { SFO }\end{array}$ & $\begin{array}{l}\text { Corn Oil } \\
\text { CO }\end{array}$ & $\begin{array}{c}\text { Rapeseed Oil } \\
\text { RO }\end{array}$ \\
\hline Sample, $N$ & 99 & 99 & 99 & 99 \\
\hline Mean, $\mu, \mathrm{kV}$ & 17.66 & 16.77 & 20.08 & 18.83 \\
\hline Variances, $\sigma^{2}$ & 19.29 & 38.83 & 46.10 & 36.86 \\
\hline Standard deviation & 4.39 & 6.23 & 6.78 & 6.07 \\
\hline Median, kV & 17.70 & 16.60 & 19.80 & 19.00 \\
\hline Variability coef, $\%$ & 33.80 & 32.23 & 24.86 & 37.13 \\
\hline Shapiro-Wilk & 0.9874 & 0.9803 & 0.9742 & 0.9925 \\
\hline Kolmogorov test & 0,0688 & 0,0563 & 0,0353 & 0,0606 \\
\hline $\begin{array}{l}\text { Normal Distribution, } \\
\mathrm{N}\left(\mu, \sigma^{2}\right)\end{array}$ & $\begin{array}{c}\mathrm{N}(17,66 ; \\
4.3917) \\
\end{array}$ & $\begin{array}{c}\mathrm{N}(16,7788 ; \\
6.23) \\
\end{array}$ & $\begin{array}{c}\mathrm{N}(20,0828 \\
6.79) \\
\end{array}$ & $\begin{array}{c}\mathrm{N}(18,8374 \\
6.07) \\
\end{array}$ \\
\hline $\begin{array}{l}\text { Lognormal } \\
\text { Distribution } \\
\log \left(\lg \mu, \sigma^{2}\right)\end{array}$ & $\begin{array}{l}\log (2.8385 \\
0.264)\end{array}$ & $\begin{array}{c}\log (2.7496 \\
0.4147)\end{array}$ & $\begin{array}{c}\log (2.9161 \\
0.471)\end{array}$ & $\begin{array}{l}\log (2.8685 \\
0.4123)\end{array}$ \\
\hline $\begin{array}{l}\text { Gamma Distribution, } \\
G(\alpha, \beta)\end{array}$ & $\begin{array}{l}\mathrm{G}(1.1492 ; \\
15.3585)\end{array}$ & $\begin{array}{l}\mathrm{G}(2.5387 \\
6.6093)\end{array}$ & $\begin{array}{l}\mathrm{G}(3.2768 ; \\
6.1289)\end{array}$ & $\begin{array}{c}\mathrm{G}(2.4815 \\
7.591)\end{array}$ \\
\hline
\end{tabular}

Table 2. Empirical parameters and estimated parameters of the distribution statistical lows obtained for the series of variables of breakdown voltage $(\mathrm{kV})$ for Mineral Oil, Sun Flower Oil, Corn Oil, Rapeseed Oil, with plan-plan electrodes

\begin{tabular}{|c|c|c|c|c|}
\hline \multirow{2}{*}{$\begin{array}{l}\text { Empirical } \\
\text { Distribution } \\
\text { Parameters } \\
\text { (Plan electrodes) }\end{array}$} & \multicolumn{4}{|c|}{ Type of Random Variables } \\
\hline & $\begin{array}{c}\text { Mineral Oil } \\
\text { TR } 30\end{array}$ & $\begin{array}{c}\text { Sun Flower Oil } \\
\text { SFO }\end{array}$ & $\begin{array}{l}\text { Corn Oil } \\
\text { CO }\end{array}$ & $\begin{array}{c}\text { Rapeseed Oil } \\
\text { RO }\end{array}$ \\
\hline Sample, $N$ & 99 & 99 & 99 & 99 \\
\hline Mean, $\mu, \mathrm{kV}$ & 14.00 & 24.54 & 19.95 & 23.03 \\
\hline Variances, $\sigma^{2}$ & 19.28 & 38.82 & 46.09 & 36.86 \\
\hline Standard deviation & 4.39 & 6.23 & 6.78 & 6.07 \\
\hline Median, kV & 14.55 & 23.40 & 11.65 & 25.25 \\
\hline Variability coef., $\%$ & 23.70 & 13.57 & 19.61 & 11.70 \\
\hline Shapiro-Wilk & 0.9874 & 0.9803 & 0.9742 & 0.9925 \\
\hline Kolmogorov test & 0.0688 & 0.0563 & 0.0353 & 0.0606 \\
\hline $\begin{array}{l}\text { Normal Distribution, } \\
N\left(\mu, \sigma^{2}\right)\end{array}$ & $\begin{array}{c}\mathrm{N}(17.66 \\
4.3917)\end{array}$ & $\begin{array}{c}\mathrm{N}(16.7788 ; \\
6.23)\end{array}$ & $\begin{array}{c}\mathrm{N}(20.0828 \\
6.79)\end{array}$ & $\begin{array}{l}\mathrm{N}(18.8374 ; \\
6.07)\end{array}$ \\
\hline $\begin{array}{l}\text { Lognormal } \\
\text { Distribution } \\
\log \left(\lg \mu, \sigma^{2}\right)\end{array}$ & $\begin{array}{c}\log (2,6082 \\
0.2617)\end{array}$ & $\begin{array}{c}\log (3,1899 \\
0.1515)\end{array}$ & $\begin{array}{l}\log (2,7213 \\
\quad 0.2012)\end{array}$ & $\begin{array}{c}\log (3.1296 \\
0.1276)\end{array}$ \\
\hline $\begin{array}{l}\text { Gamma Distribution, } \\
G(\alpha, \beta)\end{array}$ & $\begin{array}{c}\mathrm{G}(0.8744 ; \\
16.0219)\end{array}$ & $\begin{array}{c}\mathrm{G}(0.5144 ; \\
47.7115)\end{array}$ & $\begin{array}{l}\mathrm{G}(0.6045 ; \\
25.6447)\end{array}$ & $\begin{array}{c}\mathrm{G}(0.3483 ; \\
66.156)\end{array}$ \\
\hline
\end{tabular}


In the Table 1 and Table 2 are shown the values of variance coefficient $V$ for all types of oils is between 17-38\% for the voltage breakdown tests with sphere and plane electrodes. The data illustrate that oil samples are not very homogeneous. These values highlight the fact that during the tests these types of oils change their structure.

The oils ages after the 99 breakthroughs. This shows that in this case the arithmetic mean is not representative. A test with 99 successive electric breakdowns should not be representative for the initial characterization of the insulation oils. The data of Table 3 show the variance coefficient $V$ for mineral oil of $17.43 \%$ for tests with calotte electrodes, which indicates a high uniformity and highlights the fact that the oil has not changed the structure.

Table 3. Empirical parameters and estimated parameters of the distribution statistical lows obtained for the series of variables of breakdown voltage $(\mathrm{kV})$ for Mineral Oil, Sun Flower Oil, Corn Oil, Rapeseed Oil, with calotte -calotte electrodes

\begin{tabular}{|l|c|c|c|c|}
\hline \multirow{2}{*}{$\begin{array}{l}\text { Empirical Distribu- } \\
\text { tion Parameters } \\
(\text { Sphere electrodes) }\end{array}$} & \multicolumn{4}{|c|}{ Type of Random Variables } \\
\cline { 2 - 5 } & $\begin{array}{c}\text { Mineral Oil } \\
\text { TR 30 }\end{array}$ & $\begin{array}{c}\text { Sun Flower Oil } \\
\text { SFO }\end{array}$ & $\begin{array}{c}\text { Corn Oil } \\
\text { CO }\end{array}$ & $\begin{array}{c}\text { Rapeseed Oil } \\
\text { RO }\end{array}$ \\
\hline Sample, $N$ & 99 & 99 & 99 & 99 \\
\hline Mean, $\mu, \mathrm{kV}$ & 16.04 & 20.08 & 18.83 & 17.66 \\
\hline Variances, $\sigma^{2}$ & 7.82 & 36.86 & 19.28 & 36.86 \\
\hline Standard deviation & 2.79 & 6.07 & 4.39 & 6.07 \\
\hline Median, kV & 16.20 & 15.30 & 15.65 & 14.25 \\
\hline Variability coef, $\%$ & 17.43 & 33.80 & 32.23 & 24.86 \\
\hline Shapiro-Wilk & 0.9239 & 0.9742 & 0.8572 & 0.9874 \\
\hline Kolmogorov test & 0.1194 & 0.0563 & 0.0353 & 0.0606 \\
\hline Normal Distribution, & $\mathrm{N}(16.1222 ;$ & $\mathrm{N}(20.0828 ;$ & $\mathrm{N}(18.8374 ;$ & $\mathrm{N}(17.6616 ;$ \\
$\mathrm{N}\left(\mu, \sigma^{2}\right)$ & $2.8907)$ & $6.7895)$ & $6.0713)$ & $4.3917)$ \\
\hline Lognormal & $\log (2.7604 ;$ & $\log (2.9161 ;$ & $\log (2.8685 ;$ & $\log (2.8385 ;$ \\
Distribution & $0.2132)$ & $0.471)$ & $0.4123)$ & $0.264)$ \\
Log $\left(\lg \mu, \sigma^{2}\right)$ & $\mathrm{G}(0.6353 ;$ & $\mathrm{G}(3.2768 ;$ & $\mathrm{G}(2.4815 ;$ & $\mathrm{G}(1.1492 ;$ \\
\hline Gamma Distribution, & $25.3759)$ & $6.1289)$ & $7.591)$ & $15,3685)$ \\
\hline $\mathrm{G}(\alpha, \beta)$ & \multicolumn{4}{|c}{}
\end{tabular}

\section{Conclusion and Future Work}

The experimental data regarding the electric breakdown of electroinsulating oils are useful in comparative analyze of new type of oils. Research conducted for the purposes of insulating mineral oil replacement potential were targeted and vegetable oils of different types and grades, which shows similarity with the characteristics of these oils as insulating mineral oil currently used. Experimental data shows that there is compatibility of vegetable oils can be used as substitutes for mineral insulating oils.

Analysis of the experimental data illustrated that there is a normal distribution of values of each type of mineral oil and vegetable. Checking the values of some key statistical parameters lead to the formulation of the following observations: 
$\checkmark \quad$ Median and module are not significantly different from that of the arithmetic mean;

$\checkmark \quad$ Frequency distribution of rapeseed oil has two maximum;

$\checkmark \quad$ The coefficient of asymmetry is a relatively large value.

Because of the obtained asymmetry and the existence of two levels in the histograms the measurement batch of 99 tests was performed again, with new oil samples. Main statistical parameters values obtained for the new values do not differ significantly from those measured earlier.

Thus, the researches in this area have been exhausted and that they should continue to complete the final conclusions of the possibility to use organic vegetable oils as substitutes for mineral insulating oils. New research should be done relative to the type of electrodes used in ac breakdown oil testing.

\section{References}

1. Şerban, M., Helerea, E.: The Use of Vegetable Ecological Insulating Oils of High Power Transformer. In: Proceeding of International Conference (BENA) Environmental Pollution and its Impact on Public Health, pp. 120-126. Transilvania University of Brasov Press (2008)

2. Helerea, E., Munteanu, A., Serban, M.: Aspects Regarding the Monitoring and the Life Extension of Electroinsulating Oils Used in High Voltage Systems. In: Proceeding of the BRAMAT International Conference, pp. 134-138. Transilvania University of Brasov Press (2007)

3. Lvov, M.Y., Chichinskii, M.I.: Rated Indices for Evaluating the Winding Insulation Wear of Power Transformers. Power Technology and Engineering 36(5) (2002)

4. Sangeorzan, L., Helerea, E., Veştemean, D., Clotea, L.: A Statistical Approach on Load Distribution for an Industrial System. In: Optimization of Electrical and Electronic Equipments, Brasov (1998)

5. Forster, E.O., Yamashita, H., Mazzetti, C., Pompili, M., Caroli, L., Patrissi, S.: The Effect of the Electrode Gap on Breakdown in Liquid Dielectrics. IEEE-Transactions on Dielectrics and Electrical Insulation 1(3), 440-448 (1994)

6. Burnet, N.: It's a challenge for Farmers and Rape Energy Specialists. Synchronous Press, Cluj-Napoca (2004)

7. Constantinescu, I., Golumbovici, D., Militaru, C.: Processing Experimental Data with Digital Computers. Technical Publishing House, Bucuresti (1980) 